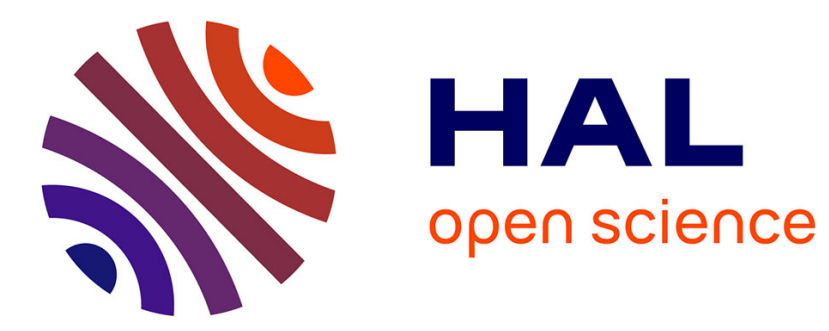

\title{
Linking canopy images to forest structural parameters : potential of a modeling framework
}

Nicolas Barbier, Pierre Couteron, Jean-Philippe Gastellu-Etchegorry, Christophe Proisy

\section{- To cite this version:}

Nicolas Barbier, Pierre Couteron, Jean-Philippe Gastellu-Etchegorry, Christophe Proisy. Linking canopy images to forest structural parameters : potential of a modeling framework. Annals of Forest Science, 2012, 69 (2), pp.305-311. 10.1007/s13595-011-0116-9 . ird-00657316v2

\section{HAL Id: ird-00657316 https://hal.ird.fr/ird-00657316v2}

Submitted on 9 Jan 2012

HAL is a multi-disciplinary open access archive for the deposit and dissemination of scientific research documents, whether they are published or not. The documents may come from teaching and research institutions in France or abroad, or from public or private research centers.
L'archive ouverte pluridisciplinaire HAL, est destinée au dépôt et à la diffusion de documents scientifiques de niveau recherche, publiés ou non, émanant des établissements d'enseignement et de recherche français ou étrangers, des laboratoires publics ou privés.

$$
\text { Copyright }
$$




\section{Editorial Manager(tm) for Annals of Forest Science Manuscript Draft}

Manuscript Number:

Title: Linking canopy images to forest structural parameters: potential of a modeling framework

Article Type: Research Paper

Keywords: texture analysis; remote sensing; 3D forest model; radiative transfer model; broad-leaf tropical forests.

Corresponding Author: Nicolas Barbier

Corresponding Author's Institution: IRD

First Author: Nicolas Barbier

Order of Authors: Nicolas Barbier;Pierre Couteron, PhD;Jean-Philippe Gastellu-Etchegorry, $\mathrm{PhD}$;Christophe Proisy, PhD

Abstract: Remote sensing methods, and in particular very high (metric) resolution optical imagery, are essential assets to obtain forest structure data that cannot be measured from the ground, because they are too difficult to measure, or because the areas to sample are too large or inaccessible. To understand what kind of, and how precisely and accurately, information on forest structure can be inverted from RS data, we propose a modeling framework combining a simple 3D forest model, Allostand, based on empirical or theoretically-derived DBH distributions and allometry rules, with a well-established radiative transfer model, DART. This framework allows producing forest canopy images for any type of forest based on widely available information of inventory data. Image texture can then be quantified, for instance using the Fourier Transform Textural Ordination (FOTO) method, and the derived textural indices compared with stand parameters for inversion and sensitivity analyses, as well as to indices from real world remote sensing images. The potential of the approach for the development of quantitative methods to assess forest structure, dynamics, matter and energy budgets and degradation, including in tropical contexts, is illustrated emphasizing broadleaf natural forests and discussed.

Suggested Reviewers: André Beaudoin

Andre.Beaudoin@RNCan-NRCan.gc.ca

Laurent Saint-André

laurent.saint_andre@cirad.fr

Richard Lucas

rml@aber.ac.uk

Sylvie Durrieu

sylvie@teledetection.fr

Uta Berger

uta.berger@forst.tu-dresden.de

Sassan Saatchi 
saatchi@congo.jpl.nasa.gov

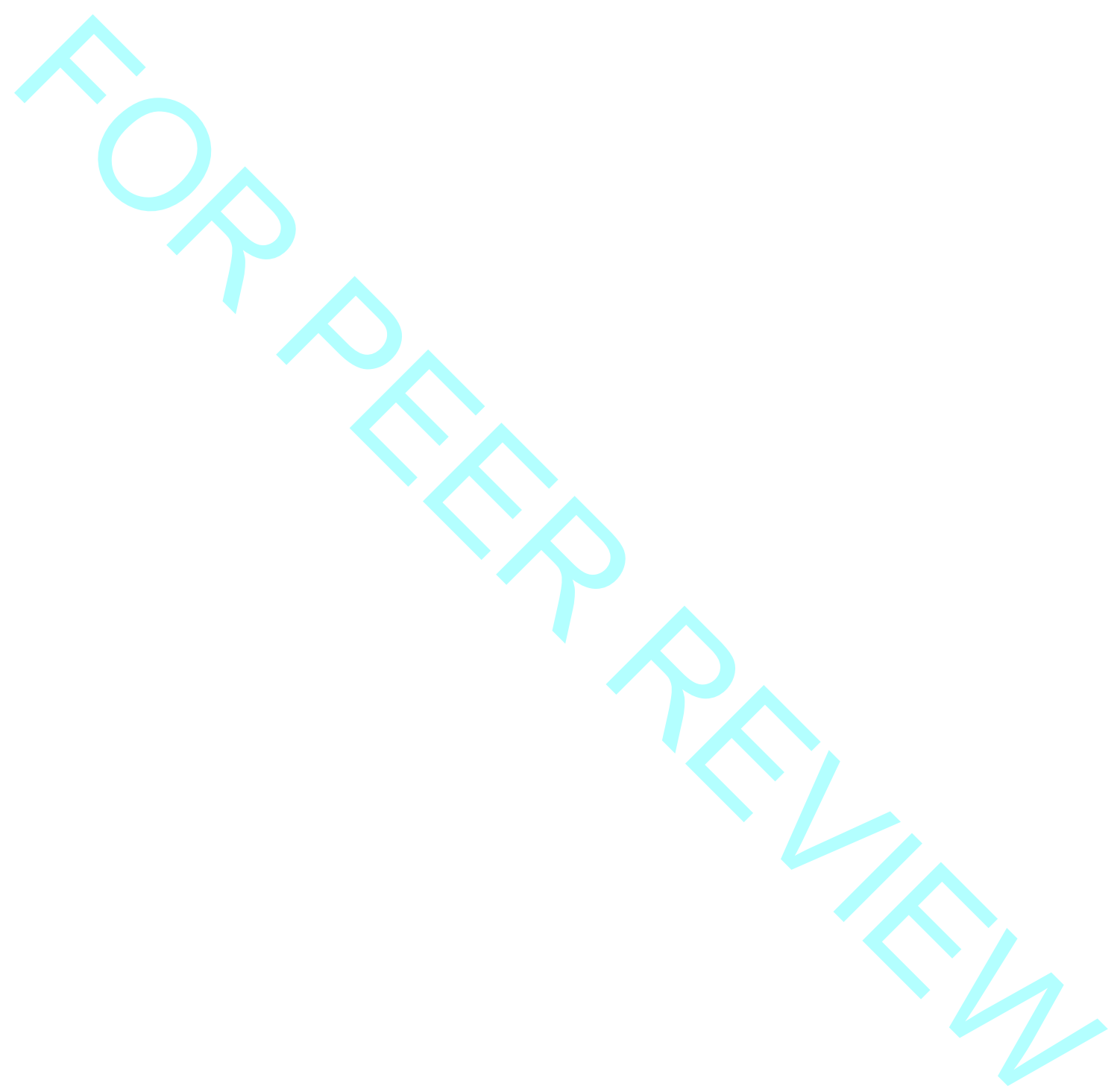


1

2 Remote sensing methods, and in particular very high (metric) resolution optical imagery, are

\section{Abstract}

essential assets to obtain forest structure data that cannot be measured from the ground, because they are too difficult to measure, or because the areas to sample are too large or inaccessible.To understand what kind of, and how precisely and accurately, information on forest structure can be inverted from RS data, we propose a modeling frameworkcombining a simple 3D forest model, Allostand, based on empiricalor theoretically-derived DBH distributionsand allometry rules, with a well-established radiative transfer model, DART. This framework allows producing forest canopy images for any type of forest based on widely available information of inventory data. Image texture can then be quantified, for instance using the Fourier Transform Textural Ordination (FOTO) method, and the derived textural indices compared with stand parameters for inversion and sensitivity analyses, as well as to indices from real world remote sensing images. The potential of the approach for the development of quantitative methods to assess forest structure, dynamics, matter and energy budgets and degradation, including in tropical contexts, is illustrated emphasizing broadleaf natural forests and discussed.

\section{Introduction}

Zenithal views of the earth surface have long contributed to forest resource inventory and planning of forest management operations(Küchler, 1967; Holdridge, 1971). Visual interpretation of aerial photographs has been used worldwide for decades to a priori delineate inventory sampling strata or to map the mosaic of forest stands on criteria relating to age, structure or dominant species(see Polidori et al., 2004 for examples of tropical applications). The classical practice shows that skilled interpreters can go beyond the mapping of strongly contrasting forest types and analyze subtler gradients of canopy aspect and map them into meaningful qualitative classes of operational value(Husch et Harrison, 1971). An important fraction of the criteria sustaining such interpretations relates to sizes and spatial distribution of both tree crowns and inter-crown gaps, which are 
observable on printed panchromatic outlooks of classical scale and resolution (1/30 000 or less), and are here referred to as canopy texture. Colour photos, including "false-colour" ones that display the near-infrared response of the vegetation can provide additional insights on species compositions. The practical, implicit message of this long-standing expertise on photo interpreting is that forest canopy aspect does convey valuable information about the forest stands.

However, this empirical expertise did neither translate into the definition of objective indices to quantify canopy aspect nor into the study of the relationship between canopy features and the most classical structural variables used by foresters, especially those which are routinely measured in field inventories. This is all the more regrettable that global challenges on climate and biodiversity urge forest science to design cost-effective systems to consistently monitor forest structures (i.e. the three dimensional arrangement of individual trees and tree parts)over extensive areas(Shugart et al., 2010).

While means for field measures are limited and often insufficient to regularly sample large areas of poor accessibility, especially in the tropics, the rapid improvement and diversification of satelliteborne sensors suggests that monitoring methods combining field and remotely-sensed data could provide cost-effective answers to the forest structure monitoring challenge(Asner et al., 2010). In fact, remote sensing approaches have the potential not only to extrapolate field results, but also to provide information that is near impossible to accurately measure on the ground, such as total height or crown size of canopy trees in multi-strata natural forests. Such information is critical since canopy structure conditions stand dynamics, gas and energy exchanges, forest feedbacks on the micro- and macro-climates and habitat for the canopy-specialized biota(Birnbaum, 2001; Bonan, 2008). Even though remote-sensing approaches using medium to high resolution data (pixels larger that $5 \mathrm{~m}$ ) have been hindered for decades by the saturation of all the physical signals at intermediate levels of forest above-ground biomass (AGB, c. 200 t/ha, Imhoff, 1995; Proisy et al., 2000), the increasing availability of very high resolution (VHR) data opens new prospects. Indeed, the VHR optical images 
furnished by satellites (e.g. Ikonos, Quickbird or GeoEye) now approach the potential of airborne photos for visual interpretation at a cheaper cost which will keep decreasing in the future.As a consequence, several studies endeavoured to extractquantitative information on canopy structure from such imagery (Bruniquel-Pinel et Gastellu-Etchegorry, 1998; Asner et al., 2002; Frazer et al., 2005; Gougeon et Leckie, 2006; Malhi et Roman-Cuesta, 2008). In particular, texture indices provided by the FOTO method (Fourier Transform Textural Ordination) showed good correlations with usual stand parameters(Couteron et al., 2005) and even biomass(Proisy et al., 2007) in some case studies carried out in natural tropical forests. These relationships remarkably appeared to hold without saturation even for very high biomass values (above $500 \mathrm{t} / \mathrm{ha}$ ).

Validating at large scale those encouraging local results is made difficult by the present lack of extensive datasets simultaneously featuring reliable field data and canopy images of sufficient spatial resolution, i.e. with pixels of $1 \mathrm{~m}$ or less. Moreover, the regional to global stability of the relationships between canopy structure (mostly pertaining to crowns) and other forest structural parameters (largely deriving from trunks diameters) remains to be assessed, despite some theoretical and empirical efforts to uncover general allometry rules at the individual and stand levels(Coomes et al., 2003; Muller-Landau, Condit, Chave, et al., 2006; Poorter et al., 2006; Enquist et al., 2009). Similarly, the influence on image texture of tree architecture, crown shape, physiology, phenology, and their variation across species, as well as the effect of different perturbation types on stand structure calls for in depth studies. Another issue is that acquisition conditions, and in particular the sun-scene-sensor angles which determines shadowing,do have an influence on texture which must be accounted for when using several or numerous images, or in the presence of marked topography(Barbier, Proisy, et al., 2010).

Thus, simulating canopy images from forest mockups of known 3D structure is appealing to anticipate the increasing availability of relevant satellite data, and extensively assess the extent to and the conditions under which forest structural stand parameters could be retrieved from canopy 
image analysis. The objectives of the approach which will be illustrated in the present paper can be

77 summarized in four steps: (i) simulating 3D explicit mockups of forest stands from the most basic

78 information provided by field inventories, namely distributions of diameter at breast height values

79 (dbh) ; (ii) applying a radiative transfer model on the mockups to generate canopy images; (iii)

80 characterizing the texture of the generated canopy images using the FOTO method; (iv) analyzing the covariation of FOTO-based texture indices and the stand parameters corresponding to the 3D mockups in order to test the potential of model inversion.

83 
The Allostand model aims at producing simple 3D forest simulations (Fig. 1) on the basis of information generally available out of classical forest inventories, i.e. densities of trees according to classes of trunk diameters at breast heights (DBH). The basic model input is therefore either an observed or a theoretical diameter frequency distribution, such as the inverse square law of Enquist et al.(2009) or alternative laws(Coomes et al., 2003). From there,the spatial distribution and sizes of trunks and crowns are produced on the basis of measured allometry rules at the individualand stand scales (see below).

To ensure its applicability over extents of poorly known forests, the present version of the model is kept at the simplest possible level(or "zeroth order" sensu West et al., 2009): tree crowns are modeled as ellipsoids, and no plastic deformations are implemented. From the DBH, allometry rules obtained, for instance from rainforest trees(Poorter et al., 2006; Muller-Landau, Condit, Chave, et al., 2006), allow computing tree height and crown dimensions. For instance one can compute crown area and tree height from DBH using the allometric exponents provided in table 2 of (2006). In absence of measured $(x, y)$ positions for each tree, these positions are obtained using an iterative hardcore(Matérn, 1986) birth/death procedure. In other words, starting from the largest tree in the DBH distribution, at each iteration step a new individual of lesser or equal size is placed at random. It is kept only if it happens to be located beyond a certain distance from preexistingtrees, otherwise a new location is taken, up to a chosen maximal attempt number. If this number is reached, a failed birth is counted. Hard core distance between trees of the same size class is taken from the isometricrelationshiplinkinginter-tree distance to DBH as derived by Enquist et al.(2009) on theoretical grounds. Minimum distance between trees of different size classes are defined empirically according to a decreasing function of the diameter difference, in a way minimizing the number of failed births. The above procedure is repeated within each size class for the number of 
individuals requested to match the DBH frequency distribution. Model output takes the form of a table listing tree individuals, their XY positions and dimensions (height plus trunk and crown radii).

To illustrate the result of a tropical rainforest simulation produced by the Allostand model, a tridimensional representation is shown in figure 1. This simulation was created using a DBH frequency distribution following theinverse square law (-2 power law with intercept $=5000$ trees $/$ ha) and with a bin width of $1 \mathrm{~cm}$, a minimum DBH of $5 \mathrm{~cm}$ and a maximum $\mathrm{DBH}\left(\mathrm{DBH}_{\max }\right)$ of $100 \mathrm{~cm}$.

\section{Modelling radiative transfer- DART model}

From the 3D stands, it is possible to simulate spectral images of the scene as viewed from air- or space-borne sensors (Fig. 2). The Discrete Anisotropic Radiative Transfer (DART) model(GastelluEtchegorry, 2008), is used to simulate the interaction between scene components and electromagnetic signals of various natures(e.g., of varying wavelengths, active or passive signals, of varying sun-scene-sensor configurations, etc.).The DART model involves an iterative tracing of rays in a discrete number of directions within a scene constituted by parallelepipedic voxels. Light transfer within a voxel depends on the proportion and orientation of volume elements (modeled as turbid, e.g. foliage, atmosphere) and surface elements (solid, e.g. trunks, soil)it contains.

From the positions and dimensions of trees produced by the Allostand model, DARTfirst computes the voxelized (discrete) scene, which involves computing the fractions and orientation of the main scene elements present in each voxel. The reflectance of each scene element in different spectral bands can be parameterized at the desired or accessible level of precision, from either general estimations or from specific measurements made for the area of interest (for instance, for foliage, from radiometric information and technical specifications of modern satellite imagery such as GeoEye $^{\circledast}$ ). Other relevant parameters used by DARTare the leaves angular distribution and density within foliage voxels, as well as the distribution of empty voxels within a tree crown. As these parameters are difficult to measure, they are usually taken empirically, in order to achieve realistic values of the Leaf Area Index (LAI) at the stand scale (e.g., LAI between 6 and 8(Richards, 1995)). 
The Fourier Transform Textural Ordination (FOTO) method basically ordinates digital images along

135 coarseness-fineness texture gradients in a way congruent with the visual appraisal (see (Couteron, 2002)for details). It showed promising results(Couteron et al., 2005; Proisy et al., 2007; Barbier, Couteron, Proisy, et Malhi, 2010) for the characterization and measure of canopy texture on very high (metric) resolution air- and space-borne panchromatic imagery. The FOTO method uses a windowed 2D Fourier transform and the derived periodograms(power spectrum; Diggle, 1989; Mugglestone et Renshaw, 1998)to characterize the textural properties of image extracts of about 1 ha. Each 2D periodogram is simplified to account only for spatial frequency (scale) information and not for possible anisotropic variations of texture. This simplification (averaging of periodogram values over the azimuths) leads to a so-called r-spectrum(Mugglestone et Renshaw, 1998)representing, for each image, the broken-down of the panchromatic reflectance variance accounted for by successive bins of spatial frequencies. Principal component analysis is then applied on the set of standardized rspectra (which may include spectra from hundreds to thousands of images)to identify the main gradients of canopy textural variation and ordinate the images accordingly. The first PCA axis generally approximates the fineness-coarseness gradient of canopy grain, most frequently linked to variations in crown sizes. Subsequent axes, when notable, may point towards specific ranges of dominant spatial frequencies (related to crown or gap sizes). PCA scores of the images against such gradients are used as continuous indices of textural variation of canopy aspect.

\section{Example}

To illustrate the interest of the Allostand+DART modeling framework, we simulated 144 panchromatic reflectance images using the same parameterization as the stands presented in figures 1 and 2, for a rangeof maximum $\mathrm{DBH}$ values ( $\mathrm{DBH}_{\max }$ from 50 to $100 \mathrm{~cm}$ by steps of $\left.10 \mathrm{~cm}\right)$. To assess the sensitivity of the results to perturbations of the DBH distribution, we also madethe density in the 

(i.e., maximum DBH and density modulation in the largest DBH class), six replicates were produced.

If we investigate the relationships (Fig. 3) between stand parametersand the main textural gradient

160 (PCA1) identified over the 144 images by the FOTO method, we find that the correlation with stand

161 density is the most sensible to the perturbation introduced in stand structure by changing the tree

162 density in the largest DBH classes. The $r^{2}$ of the regression is indeed only of 0.35 (Fig. 3a). On the

163 other hand, the correlation with mean crown diameter (Fig. 3b) or with the mean DBH or mean

164 quadratic DBH are fairly good in this case, with $\mathrm{r}^{2}$ above 0.6 . The best correlations are found with the

165 maximum DBH or the averagecrown size (Fig. 3c). This is no surprise since what is captured by

166 texture analysis concerns the structure of the top canopy and the crown size distribution of canopy

167 trees.

\section{Discussion}

The main purpose of this paper is to draw the attention of forest scientists and modelers on the potential of simulating canopy panchromatic images from forest mockups of known 3D structure.

Simulating such images could be a decisive step to help forest monitoring and forest ecology benefit

172 from the increasing availability of very high resolution space-borne imagery through a thorough

173 process of model calibration and inversion. As it has been illustrated here using a very simple

174 structure model, the simulation allows assessing the extent to which the entire modeling chain can

175 be inverted to retrieve forest structure variables from canopy reflectance information. From such an

176 approach it is possible to have some a priori knowledge on the magnitude of the prediction error

177 that is to be expected for the different variables and to efficiently design how field data should be

178 acquired to validate the inversion process in a givenecological context. In fact, the confrontation of

179 space-borne information to field inventory data has often been hindered by field sampling units

180 having size, shapeor spacing propertiesirrelevant to that purpose. This hindrance adding to the well- 
variable prediction from spatial observation often disappointing andat best revealing local

agreements of unwarranted extrapolation. Whatever the type of signal and the kind of signal analysis technique, progressin forest monitoring now requestssimulations of signal interactions with a wide range of known forest structures for inversion testing. This necessity has long been recognized for radar applications(Kasischke et Christensen, 1990; Proisy et al., 2000) but has been overlooked by most users of optical imagery(but see Bruniquel-Pinel et Gastellu-Etchegorry, 1998; Frazer et al., 2005; Widlowski et al., 2007).Developing and validating forest application forthe more recent fullwaveform LiDAR (Light Detection and Ranging)techniques also requests signal simulation on forest mockups in a way similar to what is presented here, which can be done by adapting existing radiative transfer models (Rubio et al., 2009).

Since canopy information mostly pertains to the dominant fraction of the tree population, it is obvious that the best predictions are to be expected for stand variables that are the most strongly influenced by this dominant subpopulation (e.g. basal area, quadratic mean diameter and, of course,total above-ground biomass). As illustrated here (Fig.3), less accuracy is probable for variables related to stand density which directly integrates understory trees that are not visible in the canopy. In even-aged stands, most trees are dominant or co-dominant and logically the FOTO method yielded good predictions of total AGB for even-aged mangroves (Proisy et al., 2007).

In mixed-aged stands,canopy trees only account for a small share of the overall tree number. Yet, this fraction is expected to capture most of the limiting resource (usually light) and to condition gas and energy exchanges with the atmosphere (Bonan, 2008)and thereby strongly influence the whole stand dynamics. Enquist et al. (2009) assumed one of the simplest models of stand demography, which can be traced back to de Liocourt(1898), to reach the prediction that the diameter densitydistribution should scale as a -2 power of $\mathrm{DBH}$. In the present modeling illustration, we referred to it for simplicity sake,although such a distribution is not satisfactory(Muller-Landau, Condit, Harms, et al., 2006).Other simple functions of diameter distribution predicted by competing theories(Coomes et 
al., 2003) may have been used as well to create families of 3D mockups. Above all, as underlined by

Coomes et al. (2003) the size distribution of the largest trees is probably shaped by disturbances rather than neighborhood competition and is therefore barely predictable from a general reasoning. Since there is a top-down control on the stand structure (as in our Allostand simulation process), random variations in the abundances of larger treesalso propagate into the size distribution of smaller individuals. This is what we illustrated here by letting the density vary in the largest DBH class as a rudimentary way to parameterize a family of mockups. Ongoing developments include the simulations of mockups and canopy images from real-world diameter distributions observed by extensive inventories in central Africa.They also feature the prospect to deduce the mockups as outputs of more realistic simulators of forest dynamics (e.g. STRETCH, Vincent et Harja, 2008). However, most existing simulators are still highly context-specific and demanding in terms of costly diachronic data. They may also feature structural rules of unknown robustness outside the particular situation they have been devised to mimic.

As a consequence, simple modeling rules are still relevant to address the linking of stand structure and canopy images over extensive areas which are still devoid of reference data and simulators, especially in the tropics. The suite of modeling steps leading to canopy images should and could nevertheless be parsimoniously improved by verifying or calibrating the fundamental parameters for tree allometries and foliage reflectance for broad classes of forest. Simple simulation-based modeling approaches coupled with field case studies(Couteron et al., 2005; Proisy et al., 2007; Barbier, Couteron, Proisy, Malhi, et Gastellu-Etchegorry, 2010) have already demonstrated that some important stand parameters, including AGB, can be predicted from canopy images in heterogeneous natural forests. Enhanced modeling procedures will contribute to better assess the validity domains and the errors to be expected for such predictions.

\section{References}

Asner, G.P., Powell, G.V., Mascaro, J., Knapp, D.E., Clark, J.K., Jacobson, J., Kennedy-Bowdoin, T., Balaji, A., Paez-Acosta, G., Victoria, E., others, 2010. High-resolution forest carbon stocks and 
emissions in the Amazon. Proceedings of the National Academy of Sciences 107, 16738.

Asner, G.P., Palace, M., Keller, M., Pereira, R., Silva, J.N.M., Zweede, J.C., 2002. Estimating canopy structure in an Amazon Forest from laser range finder and IKONOS satellite observations. Biotropica 34, 483-492.

Barbier, N., Couteron, P., Proisy, C., Malhi, Y., 2010. The variation of apparent crown size and canopy heterogeneity across lowland Amazonian forests. Global Ecology and Biogeography 19, 7284.

Barbier, N., Couteron, P., Proisy, C., Malhi, Y., Gastellu-Etchegorry, J.P., 2010. The variation of apparent crown size and canopy heterogeneity across lowland Amazonian forests. Global Ecology and Biogeography 19, 72-84.

Barbier, N., Proisy, C., Couteron, P., Véga, C., 2010. Bidirectional texture function of LiDAR hillshade models of tropical forest canopy. Remote Sensing of Environment doi:10.1016/j.rse.2010.08.015.

Birnbaum, P., 2001. Canopy surface topography in a French Guiana forest and the folded forest theory. Plant Ecology 153, 293-300.

Bonan, G.B., 2008. Forests and climate change: Forcings, feedbacks, and the climate benefits of forests. Science 320, 1444-1449.

Bruniquel-Pinel, V., Gastellu-Etchegorry, J.P., 1998. Sensitivity of texture of high resolution images of forest to biophysical and acquisition parameters. Remote Sensing of Environment 65, 61-85.

Coomes, D.A., Duncan, R.P., Allen, R.B., Truscott, J., 2003. Disturbances prevent stem size-density distributions in natural forests from following scaling relationships. Ecology letters 6, 980989.

Couteron, P., 2002. Quantifying change in patterned semi-arid vegetation by Fourier analysis of digitized aerial photographs. International Journal of Remote Sensing 23, 3407-3425.

Couteron, P., Pelissier, R., Nicolini, E.A., Paget, D., 2005. Predicting tropical forest stand structure parameters from Fourier transform of very high-resolution remotely sensed canopy images. Journal of Applied Ecology 42, 1121-1128.

De Liocourt, F., 1898. De l'amenagement des Sapinieres. Bulletin de la Société forestière des FrancheComte et du Territorie de Belfort 4, 396-409.

Diggle, P., 1989. Time series : a biostatistical introduction. Oxford University Press, Oxford ; New York.

Enquist, B.J., West, G.B., Brown, J.H., 2009. Extensions and evaluations of a general quantitative theory of forest structure and dynamics. Proceedings of the National Academy of Sciences of the United States of America 106, 7046-7051.

Foody, G.M., 2003. Remote sensing of tropical forest environments: towards the monitoring of environmental resources for sustainable development. International Journal of Remote Sensing 24, 4035-4046.

Frazer, G.W., Wulder, M.A., Niemann, K.O., 2005. Simulation and quantification of the fine-scale spatial pattern and heterogeneity of forest canopy structure: A lacunarity-based method designed for analysis of continuous canopy heights. Forest Ecology and Management 214, 65-90.

Gastellu-Etchegorry, J.P., 2008. 3D modeling of satellite spectral images, radiation budget and energy budget of urban landscapes. Meteorology and Atmospheric Physics 102, 187-207.

Gougeon, F.A., Leckie, D.G., 2006. The individual tree crown approach applied to Ikonos images of a coniferous plantation area. Photogrammetric Engineering and Remote Sensing 72, 12871297.

Holdridge, L.R., 1971. Forest environments in tropical life zones: a pilot study. Pergamon Press. Husch, B., Harrison, J.D., 1971. Planning a forest inventory. Bernan Press (PA).

Imhoff, M.L., 1995. Radar backscatter and biomass saturation: ramifications for global biomass inventory. Geoscience and Remote Sensing, IEEE Transactions on 33, 511-518.

Kasischke, E.S., Christensen, N.L., 1990. Connecting forest ecosystem and microwave backscatter models. International Journal of Remote Sensing 11, 1277-1298. 
Küchler, A.W., 1967. Vegetation mapping. Ronald Press Co.

Malhi, Y., Roman-Cuesta, R.M., 2008. Analysis of lacunarity and scales of spatial homogeneity in IKONOS images of Amazonian tropical forest canopies. Remote Sensing of Environment 112, 2074-2087.

Matérn, B., 1986. Spatial variation. Springer-Verlag.

Mugglestone, M.A., Renshaw, E., 1998. Detection of geological lineations on aerial photographs using two-dimensional spectral analysis. Computers \& Geosciences 24, 771-784.

Muller-Landau, H.C., Condit, R.S., Chave, J., Thomas, S.C., Bohlman, S.A., Bunyavejchewin, S., Davies, S., Foster, R., Gunatilleke, S., Gunatilleke, N., Harms, K.E., Hart, T., Hubbell, S.P., Itoh, A., Kassim, A.R., LaFrankie, J.V., Lee, H.S., Losos, E., Makana, J.R., Ohkubo, T., Sukumar, R., Sun, I.F., Supardi, N.M.N., Tan, S., Thompson, J., Valencia, R., Munoz, G.V., Wills, C., Yamakura, T., Chuyong, G., Dattaraja, H.S., Esufali, S., Hall, P., Hernandez, C., Kenfack, D., Kiratiprayoon, S., Suresh, H.S., Thomas, D., Vallejo, M.I., Ashton, P., 2006. Testing metabolic ecology theory for allometric scaling of tree size, growth and mortality in tropical forests. Ecology Letters 9, 575588.

Muller-Landau, H.C., Condit, R.S., Harms, K.E., Marks, C.O., Thomas, S.C., Bunyavejchewin, S., Chuyong, G., Co, L., Davies, S., Foster, R., Gunatilleke, S., Gunatilleke, N., Hart, T., Hubbell, S.P., Itoh, A., Kassim, A.R., Kenfack, D., LaFrankie, J.V., Lagunzad, D., Lee, H.S., Losos, E., Makana, J.R., Ohkubo, T., Samper, C., Sukumar, R., Sun, I.F., Supardi, N.M.N., Tan, S., Thomas, D., Thompson, J., Valencia, R., Vallejo, M.I., Munoz, G.V., Yamakura, T., Zimmerman, J.K., Dattaraja, H.S., Esufali, S., Hall, P., He, F.L., Hernandez, C., Kiratiprayoon, S., Suresh, H.S., Wills, C., Ashton, P., 2006. Comparing tropical forest tree size distributions with the predictions of metabolic ecology and equilibrium models. Ecology Letters 9, 589-602.

Polidori, L., Couteron, P., Gond, V., Proisy, C., Trichon, V., 2004. Télédétection et caractérisation des paysages amazoniens. Revue Forestière Française 101-117.

Poorter, L., Bongers, L., Bongers, F., 2006. Architecture of 54 moist-forest tree species: Traits, tradeoffs, and functional groups. Ecology 87, 1289-1301.

Proisy, C., Couteron, P., Fromard, F., 2007. Predicting and mapping mangrove biomass from canopy grain analysis using Fourier-based textural ordination of IKONOS images. Remote Sensing of Environment 109, 379-392.

Proisy, C., Mougin, E., Fromard, F., Karam, M.A., 2000. Interpretation of polarimetric radar signatures of mangrove forests. Remote Sensing of Environment 71, 56-66.

Richards, P.W., 1995. The tropical rain forest : an ecological study. Cambridge University Press, Cambridge ; New York.

Rubio, J., Grau, E., Sun, G., Gastellu Etchgorry, J., Ranson, K.J., 2009. Lidar modeling with the 3D DART model, dans: AGU Fall Meeting Abstracts. p. 0330.

Shugart, H.H., Saatchi, S., Hall, F.G., 2010. Importance of structure and its measurement in quantifying function of forest ecosystems. Journal of Geophysical Research 115.

Vincent, G., Harja, D., 2008. Exploring ecological significance of tree crown plasticity through threedimensional modelling. Annals of Botany 101, 1221-1231.

West, G.B., Enquist, B.J., Brown, J.H., 2009. A general quantitative theory of forest structure and dynamics. Proceedings of the National Academy of Sciences of the United States of America 106, 7040-7045.

Widlowski, J.L., Taberner, M., Pinty, B., Bruniquel-Pinel, V., Disney, M., Fernandes, R., GastelluEtchegorry, J.P., Gobron, N., Kuusk, A., Lavergne, T., others, 2007. Third Radiation Transfer Model Intercomparison (RAMI) exercise: Documenting progress in canopy reflectance models. Journal of Geophysical Research 112, D09111. 


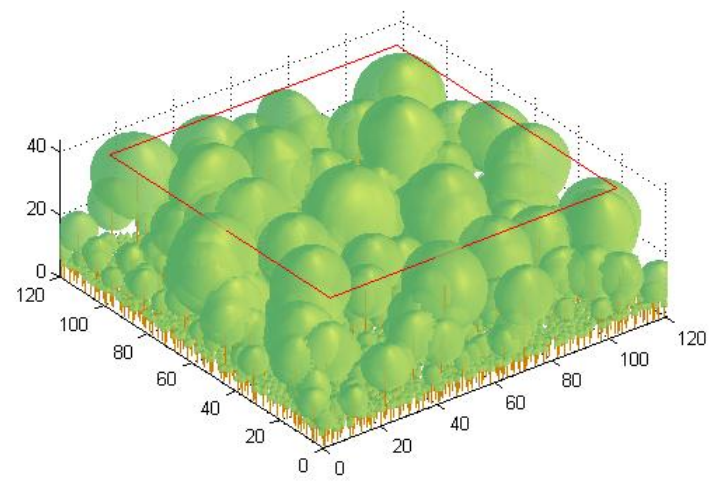

332

333 Figure 1. View of a forest stand produced by the Allostand model on the basis of a inverse square law DBH

334 distribution(Enquist et al., 2009), and using rainforest tree allometries(Poorter et al., 2006; Muller-Landau,

335 Condit, Chave, et al., 2006). The superimposed square area represents the 1 ha plot used in subsequent

336 analyses. 


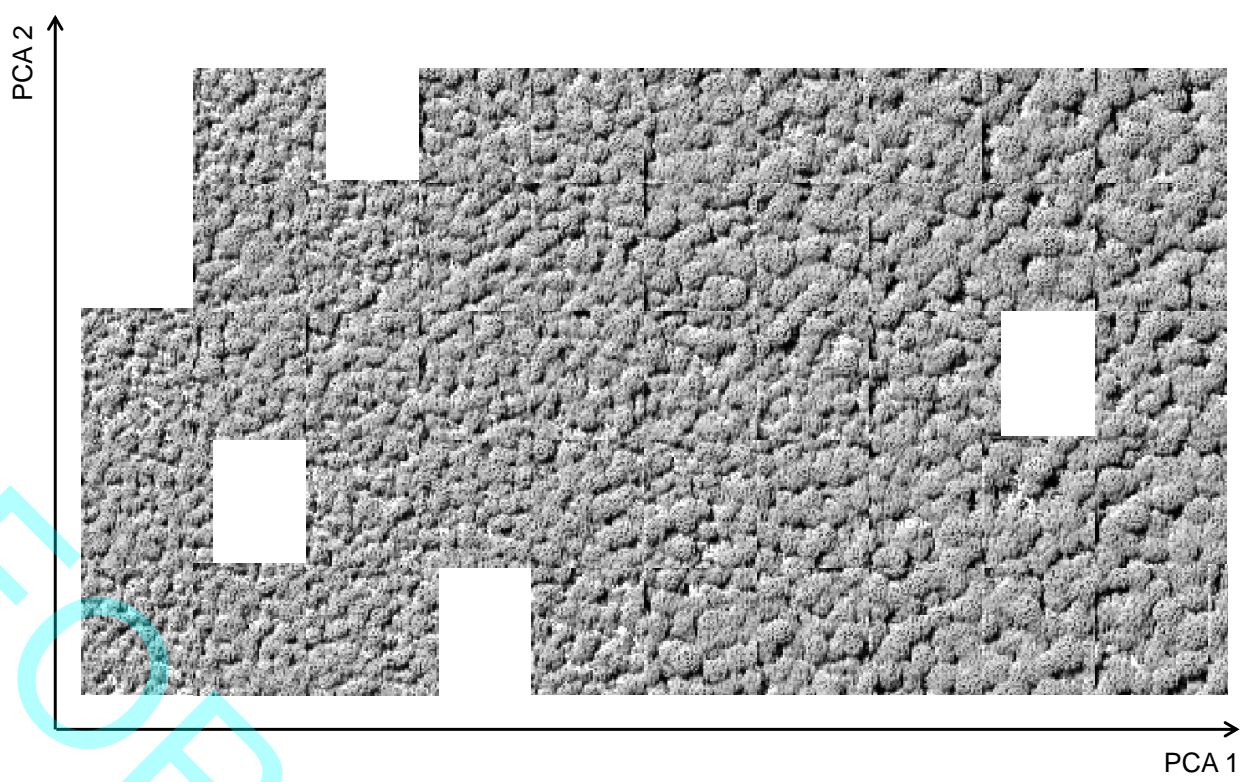

339 Figure 2. Array of panchromatic images produced by the DART radiative transfer model using Allostand 3D

340 forest simulations. The images are sampled and sorted along the two main textural gradients identified by the

341 Fourier transform textural ordination (FOTO) method applied 144 images simulated with varying $\mathrm{DBH}_{\text {max }} \mathrm{and}$ interpretation of the second gradient (PCA 2) is more difficult, but it represents density variations (see text). 


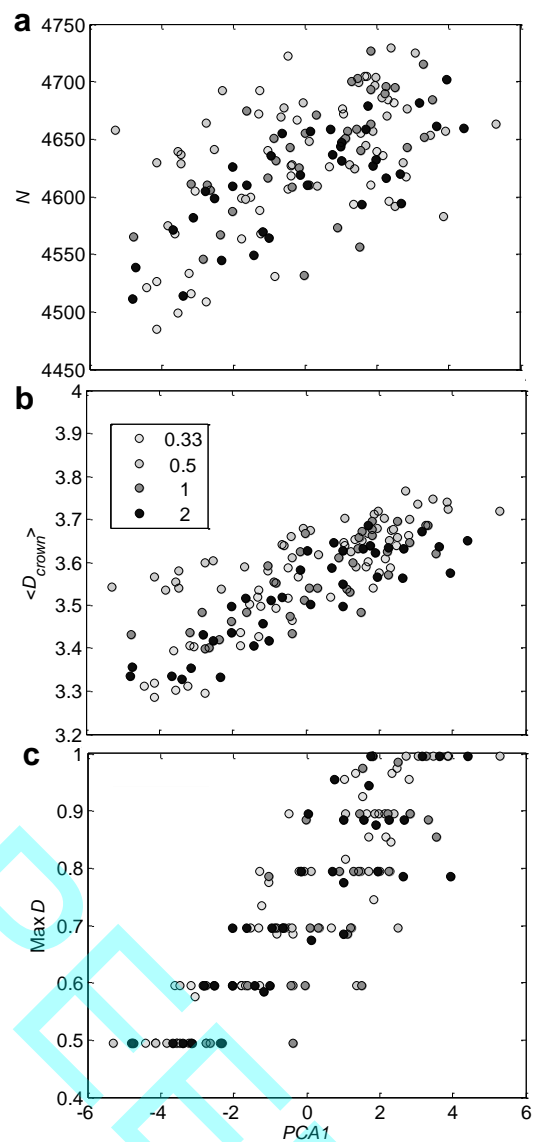

345 Figure 3. Relationship between some classical forest parameters of the Allostand simulated forests and the main textural gradient identified by the FOTO method on the simulated mages (PCA1). (a) Total stand density,

347 [stems of $\left.D B H>2 \mathrm{~cm} \mathrm{ha}^{-1}\right] ; \mathrm{r}^{2}=0.35$. (b) Mean crown diameter $[\mathrm{m}] ; \mathrm{r}^{2}=0.62$, (c) Maximum DBH value $[\mathrm{m}] ; \mathrm{r}^{2}=0.75$. Allostand simulations were produced on the basis of a -2 power law DBH distribution and with varying DBH max values ( 50 to $100 \mathrm{~cm}$ by steps of $10 \mathrm{~cm}$ ). Noise has been introduced by varying the density in the largest DBH class by a factor of either $0.33,0.5,1$ or 2 (see inset in (b) for the symbols of the four classes). 


\title{
Linking canopy images to forest structural parameters:
}

\section{potential of a modeling framework}

\author{
NicolasBARBIER ${ }^{1^{*}}$ \\ Pierre COUTERON ${ }^{1}$ \\ Jean-Philippe GASTELLY-ETCHEGORRY ${ }^{2}$ \\ Christophe PROISY ${ }^{1}$ \\ ${ }^{1}$ IRD-UMR AMAP, Boulevard de la Lironde, TA A-51/PS2, 34398 Montpellier Cedex 05, France \\ *nicolas.barbier@ird.fr \\ ${ }^{2}$ Centre d'Etudes Spatiales de la Biosphère (CESBIO). Université de Toulouse, UPS, CNRS, CNES, IRD, \\ 18 Av. Ed. Belin, 31401, Toulouse, France \\ Running head: Linking forest canopy images to field inventory data \\ Keywords: texture analysis/remote sensing/ 3D forest model /radiative transfer model / broad-leaf \\ tropical forests
}

Characters: 31166

Figures: 3 